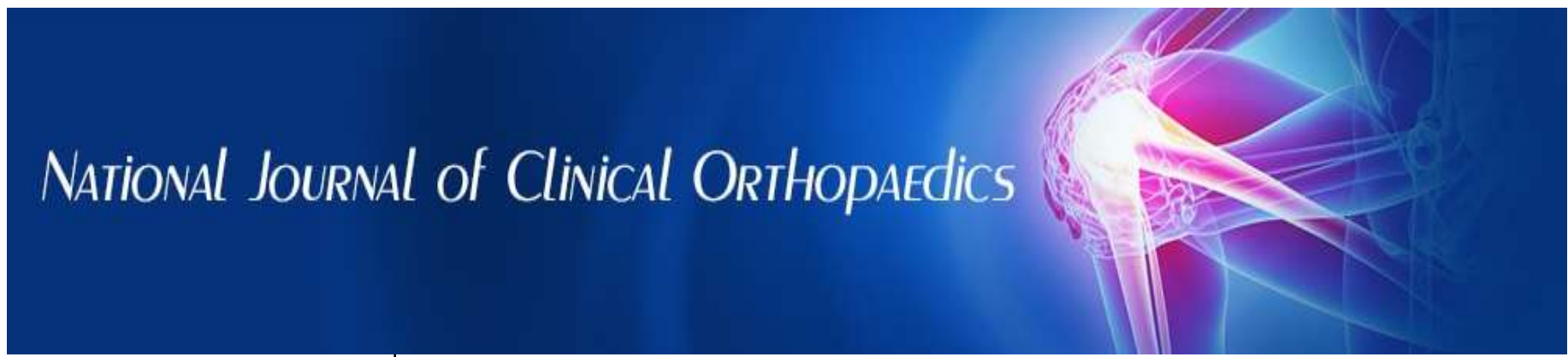

ISSN (P): 2521-3466

ISSN (E): 2521-3474

(C) Clinical Orthopaedics www.orthoresearchjournal.com 2021; 5(2): 01-03

Received: 09-01-2021

Accepted: 19-02-2021

\section{Yasim Khan}

MS Ortho, DNB Ortho,

Department of Orthopaedic Surgery, Maulana Azad Medical College and Associated Lok Nayak Hospital, New Delhi, Delhi, India

\section{Shreesh Kadur JM}

MS Ortho, DNB Ortho, Sky Superspecaility Hospital, Iritty, Kannur, Kerala, India

Sumit Arora

MS Ortho, DNB Ortho, MNAMS, MRCPS (Glasgow), Department of Orthopaedic Surgery, Maulana Azad Medical College and Associated Lok Nayak Hospital, New Delhi, Delhi, India

\section{Anil Dhal}

MS Ortho, Department of Orthopaedics Surgery, ESI Hospital, Faridabad, Haryana, India
Corresponding Author:

Shreesh Kadur JM

MS Ortho, DNB Ortho, Sky

Superspecaility Hospital, Iritty,

Kannur, Kerala, India

\section{Fibular regenerate for revision bone grafting procedure}

\author{
Yasim Khan, Shreesh Kadur JM, Sumit Arora and Anil Dhal
}

DOI: https://doi.org/10.33545/orthor.2021.v5.i2a.271

\begin{abstract}
Sequestrectomy in chronic osteomyelitis leads to large bony defect in some cases. It needs segemental bone grafting of which fibula is commonly used in children. Few instances might need revision graft due to fracture. We have done a technique of periosteal sparing fibular graft removal in a 9 year old child with the usage of regenerate of the same side for revision procedure. Donor and recipient site healed at 6 months and 2 years respectively with no ankle deformity. This is an easy and versatile technique which can be extrapolated to several other disorders requiring repeated bone graft.
\end{abstract}

Keywords: Bone graft, fibula, non-union, delayed union, non-vascularized fibula

\section{Introduction}

Chronic osteomyelitis in young children causes considerable morbidity due to limb length inequality by growth arrest or bony overgrowth ${ }^{[1]}$. Treatment includes eradication of infection by excision of infected bone, administration of antibiotics and enhancing the nutrition. Sequestrectomy, the excision of infected bone sometimes lead to large longitudinal bony defect which needs bone grafting. There are various techniques for bone grafting ${ }^{[2]}$. Fibular bone grafting is one of the commonly done procedure in the paediatric age group. Unfortunately, some cases may require revision bone grafting also. We have described a technique of re-harvesting of fibular regenerate from the previous fibular bone graft donor site. We decided to use the woven fibular regenerate rather than a cortical strut of fibula from another leg to give a better chance for graft incorporation in the host bed and to avoid another scar on the contralateral lower limb.

\section{Case history}

A 9-years-old girl presented with large gap non-union of ulna secondary to healed chronic osteomyelitis with radial head dislocation in the dominant limb (Fig. 1A). A non-vascularized fibular strut grafting of $8 \mathrm{~cm}$ in length was done. The graft united at both ends, but a graft fracture occurred after 6 months (Fig. 1B). We planned to do a revision bone grafting. Since the previous donor site of fibula had regenerated but without cortical differentiation (Fig. 1C), we decided to take the graft from the regenerate of donor site for the revision procedure. Following were the steps of the technique used:

- Step 1: Fibula was approached from the previous posterolateral incision. The segment of fibula without cortical differentiation was harvested preserving the periosteal layer ${ }^{[3]}$. A length of $6 \mathrm{~cm}$ of distal fibula was left after harvesting the graft.

- Step 2: Recipient site was approached through the incision of previous surgery.

- Step 3: Recipient site prepared, revision graft was fixed with screw and K-wires with minimally disturbing the already incorporated graft from the first grafting procedure.

- Step 4: Adequate soft tissue coverage was given to graft and closure was done.

- Step 5: Postoperatively cast was applied for 6 weeks and after that, a functional brace was given.

Revision grafting procedure was successful and the graft got united in 6 month duration (figure 1D). 
There were no episodes of re fracture (follow x-ray in figure 2, three years post-surgery). The donor site of fibula also got united in 2 years. Fibula station (grade 1), as per Malhotra grading [4] didn't change and there was no valgus in the ankle clinically when compared with the opposite side. (Figure 3)

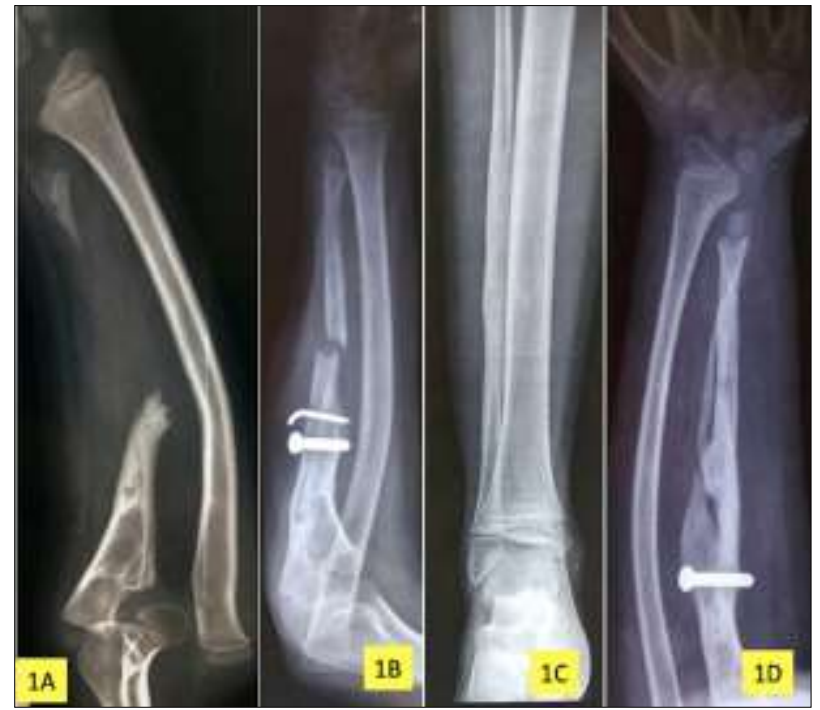

Fig 1: Serial relevant radiographs of the 9-years-old girl: (A) Preoperative radiograph of the forearm showing large gap non-union of the ulna with dislocation of the radial head, (B) Postoperative radiographs showing good union at the proximal and distal end with fractured graft at 6 months, (C) Fibular bone regenerate after 6 months, (D)

Postoperative radiograph showing good consolidation at 18 months follow-up

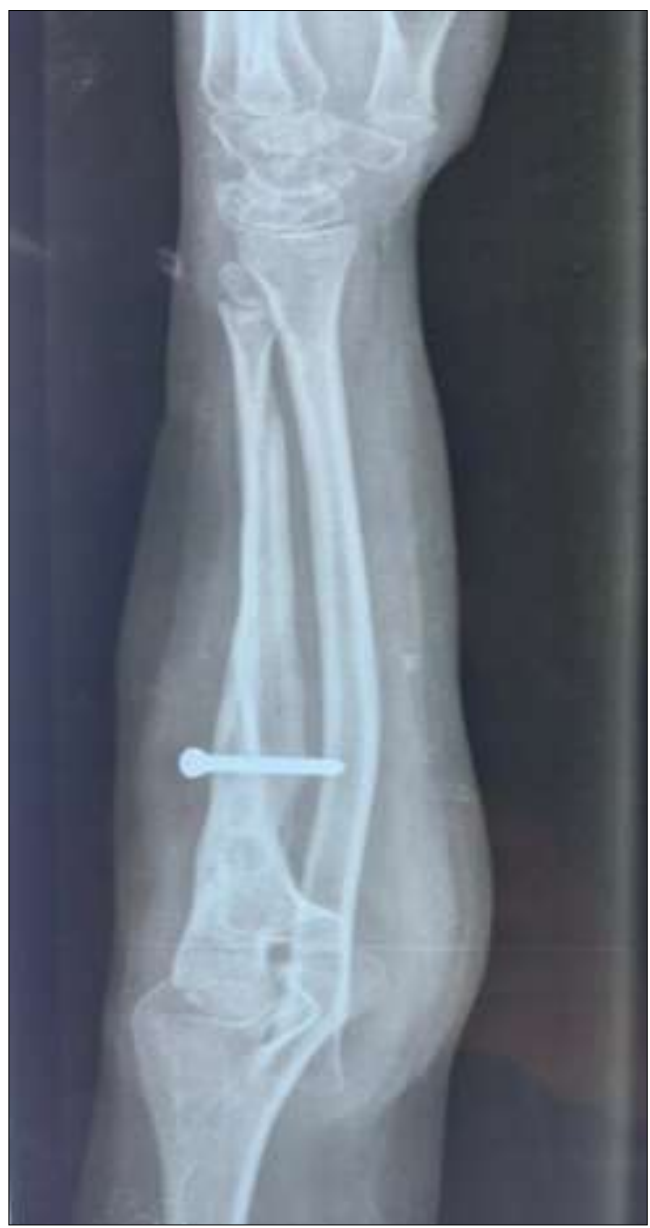

Fig 2: 3 years follow up radiograph of forearm showing complete incorporation of graft at ulna

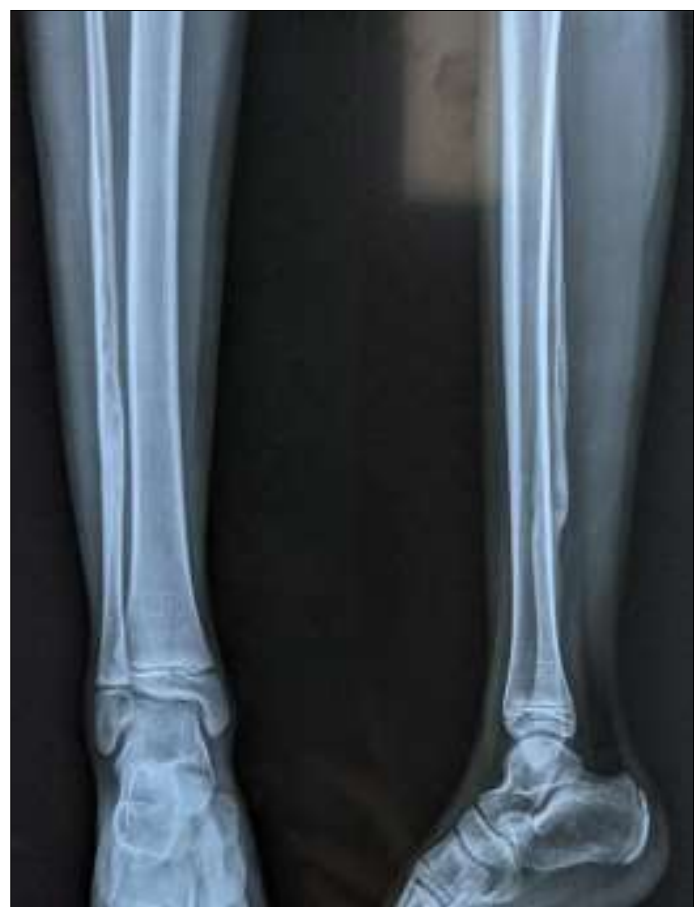

Fig 3: 3 years follow up radiograph of leg showing complete regeneration with corticomedullary differentiation of donor site (fibula)

\section{Discussion}

Bone grafts are broadly divided into autografts, allografts, synthetics and others based on their harvesting tissue. Based on their properties and mechanism to form new bone they can be classified as Osteoconductive (calcium sulphate, calcium phosphate, biocative glass, ceramics etc.)includes formation of bone by providing passive porous scaffold; osteoinductive (demineralized bone matrix, bone morphogenic proteins, growth factors etc..) includes bone formation by differentiation of stem cells into osteoogenic cells; osteogeneic (bone marrow aspirate) includes formation of bone by providing stem cells with osteogenic potential and the combined (composites) ${ }^{[5]}$.

Chronic osteomyelitis requiring sequestrectomy may leave a gap nonunion. These require segmental grafts which may be nonvascularised or vascularised pedicle or free grafts. The advantage of vascularised grafts is that they do not rely on revascularisation and therefore should become fully incorporated sooner. However, it is a technically demanding procedure with a high rate of thrombosis of the graft vessels. Non-vascularised grafts are technically much easier to use and have been successful in children and adults $[2,6,7]$

Among the segmental autografts, fibula is used commonly in children. Fibula carries $1 / 6$ of static load on the leg to the talus. Removal of a part of fibula will leave a gap and the stability of the distal stump depends on interosseous membrane and the anterior inferior talofibular ligament. Studies have shown that distal 10 percent ${ }^{[8]}$ or $6-7 \mathrm{~cm}^{[9]}$ of fibula is necessary for the ankle stability. Some of them have inferred patients with age greater than 8 year didn't develop ankle deformity ${ }^{[10]}$.

In our study we practised periosteal sparing fibular segmental autograft and we had left around $6 \mathrm{~cm}$ of distal fibula. There was no ankle deformity in the 3 year follow up time. We used fibular regenerate than the contralateral normal fibula for the revision grafting. The reason behind it was the regenerate woven bone which is porous in nature would incorporate in the host bed easily and faster than the cortical strut which gets incorporated by creeping substitution ${ }^{[11]}$. The cortical strut may have risk to get fractured. Expected complications in this technique are 
1. Graft fracture stays one of the most troubling complications which can be avoided with proper immobilization and parental counselling to avoid trauma.

2. Joint stiffness can be addressed by adequate physiotherapy.

3. In case of inability to place hardware for graft fixation, coated polyester suture may be used to fix graft.

4. Non-union of fibular graft donor site may occur in some cases as the blood supply is precarious in the middle and distal third junction ${ }^{[12]}$.

5. Sural nerve injury should be avoided while harvesting graft.

6. Valgus deformity of ankle joint may occur ${ }^{[12]}$.

\section{Limitations}

This technique has a specific window period for revision bone grafting during which the donor site fibula is in woven state. During this period the regenerate can only be harvested.

\section{Statement of consent}

Informed written consent was obtained from the parents of the patient for publication of photos and the data for educational purpose

\section{Conflict of interest: none}

\section{References}

1. Bates J. Bone overgrowth in chronic osteomyelitis in children. In Procs Association of Surgeons of East Africa conference 2003.

2. Steinlechner CW, Mkandawire NC. Non-vascularised fibular transfer in the management of defects of long bones after sequestrectomy in children. The Journal of bone and joint surgery. British volume 2005;87(9):1259-63.

3. Xin ZF, Kim KH, Jung ST. Regeneration of the fibula using a periosteum-preserving technique in children. Orthopedics 2009;32(11).

4. Malhotra D, Puri RA, Owen R. Valgus deformity of the ankle in children with spina bifida aperta. The Journal of bone and joint surgery. British volume 1984;66(3):381-5.

5. Roberts TT, Rosenbaum AJ. Bone grafts, bone substitutes and orthobiologics: the bridge between basic science and clinical advancements in fracture healing. Organogenesis 2012;8(4):114-24.

6. Yajima H, Tamai S, Mizumoto S, Inada Y. Vascularized fibular grafts in the treatment of osteomyelitis and infected non-union. Clinical orthopaedics and related research 1993;293:256-64.

7. Minami A, Kasashima T, Iwasaki N, Kato H, Kaneda K. Vascularised fibular grafts. J Bone Joint Surg [Br] 2000;82(B):1022-5.

8. Pacelli LL, Gillard J, McLoughlin SW, Buehler MJ. A biomechanical analysis of donor-site ankle instability following free fibular graft harvest. JBJS 2003;85(4):597603.

9. Garrett A, Ducic Y, Athre RS, Motley T, Carpenter B. Evaluation of fibula free flap donor site morbidity. American journal of otolaryngology 2006;27(1):29-32.

10. Sulaiman AR, Wan Z, Awang S, Che Ahmad A, Halim AS, Ahmad Mohd Zain R. Long-term effect on foot and ankle donor site following vascularized fibular graft resection in children. Journal of Pediatric Orthopaedics B 2015;24(5):450-5.

11. Burchardt H. The biology of bone graft repair. Clinical orthopaedics and related research 1983;174:28-42.

12. Agarwal A. The regeneration at non vascularized fibular harvest site and development of ankle valgus in donor leginvestigations done over two time points. Journal of clinical orthopaedics and trauma 2019;10(5):999-1003. 